\title{
Erratum to: Preconcentration and determination of lead and cadmium levels in blood samples of adolescent workers consuming smokeless tobacco products in Pakistan
}

\author{
Sadaf Sadia Arain • Tasneem Gul Kazi • Hassan Imran Afridi • Kapil Dev Brahman • \\ Naeemullah • Sumaira Khan • Abdul Haleem Panhwar • Muhammad Afzal Kamboh • \\ Jamil R. Memon
}

Published online: 30 July 2015

(C) Springer International Publishing Switzerland 2015

Erratum to: Environ Monit Assess (May 2015) 187, Issue 5:4543

DOI 10.1007/s10661-015-4543-1

The original version of this article contained a mistake.

The corrected version of the paragraph is shown below in bold.

A Perkin-Elmer Model A Analyst 700 (Norwalk, CT, USA) flame atomic absorption spectrophotometer was

The online version of the original article can be found at http://dx. doi.org/10.1007/s10661-015-4543-1.

S. S. Arain $(\bowtie) \cdot$ T. G. Kazi • H. I. Afridi • K. D. Brahman •

Naeemullah $\cdot$ S. Khan $\cdot$ A. H. Panhwar

National Center of Excellence in Analytical Chemistry,

University of Sindh, Jamshoro 76080, Pakistan

e-mail: ssadiashafi@gmail.com

T. G. Kazi

e-mail: tgkazi@yahoo.com

H. I. Afridi

e-mail: hassanimranafridi@yahoo.com

K. D. Brahman

e-mail:kr_brahman@yahoo.com

Naeemullah

e-mail: naeemullah433@yahoo.com used for metals analysis. The hollow cathode lamp of $\mathrm{Cd}$ and $\mathrm{Pb}$ were run under the conditions suggested by the manufacturer. Overall analysis was carried out with an air/acetylene flame, using $10 \mathrm{~cm}$ long slot-burner head and without any background correction. The $100 \mu \mathrm{l}$ of the samples was injected through self-made injection system of Teflon funnel and Eppendorf Pipette.

S. Khan

e-mail: skhanzai@gmail.com

A. H. Panhwar

e-mail: haleem_analyst@yahoo.com

M. A. Kamboh

Department of Chemistry, Faculty of Science, Universiti

Teknologi, Johor Bahru, Malaysia

e-mail: afzal82_kamboh@yahoo.com

J. R. Memon

Dr. M.A. Kazi Institute of Chemistry, University of Sindh,

Jamshoro, Pakistan

e-mail: memon.jamil@gmail.com 